\title{
Functional conservation of mitochondrial RNA levels despite divergent mtDNA organization
}

\author{
James P. Held ${ }^{1,2}$ and Maulik R. Patel ${ }^{2,3,4^{*}}$ (D)
}

\begin{abstract}
Objective: Mitochondria-encoded ribosomal RNA (rRNA) genes in humans are expressed at a higher rate than protein coding genes of the mitochondria. The organization of the human mitochondrial genome (mtDNA) is amenable to differential expression of rRNAs as the rRNA encoding genes lie in tandem immediately downstream of the promoter-containing region. However, mtDNA is not organized in the same way as humans in all metazoans. In the nematode, Caenorhabditis elegans, the rRNA genes are on opposite sides of the mtDNA molecule and there are no obvious promoter sequences specific to the rRNA genes. Thus, we asked whether rRNA levels are higher relative to mRNAs in mitochondria of $C$. elegans as they are in humans.

Results: Using droplet digital PCR, we discovered that steady-state mitochondrial rRNA transcript levels are approximately 120 times higher than the levels of mitochondrial mRNAs. These data demonstrate that despite the lack of conservation in mitochondrial genome organization, a high mitochondrial rRNA-to-mRNA ratio is a conserved feature of metazoans.
\end{abstract}

Keywords: Mitochondria, mtDNA, Ribosomal RNA, Droplet digital PCR, Caenorhabditis elegans

\section{Introduction}

As some of the most ancient and essential structural components of ribosomes, rRNAs constitute the majority of total cellular RNA in both prokaryotes and eukaryotes. Mitochondria contain their own ribosomes, which are, in part, composed of two rRNAs encoded by the organellar genome, mtDNA. In humans, genes encoded by mtDNA are transcribed as polycistrons, which are subsequently processed into discrete transcripts [1]. Higher mitochondrial rRNA levels relatively to mRNA are in part accounted for by about 2.5 times higher stability of structured rRNAs [2]. Additionally, in humans, mitochondrial rRNAs are calculated to be synthesized at a rate 50 to 100

\footnotetext{
*Correspondence: maulik.r.patel@vanderbilt.edu

${ }^{2}$ Department of Biological Sciences, Vanderbilt University, Nashville, TN 37232, USA

Full list of author information is available at the end of the article
}

times higher than for mRNAs [2]. Higher expression of mitochondrial rRNAs relative to mRNAs appears to be made possible by the organization of mtDNA $[2,3]$. In humans, the two rRNA encoding genes are positioned in tandem, and lie directly downstream of a promoter-containing region [4] (Fig. 1a). This arrangement is thought to allow the rRNA genes to be transcribed independently from their own promoter called heavy strand promoter 1 (HSP1) [4-6]. Termination of the resulting polycistron immediately downstream of the second rRNA gene ensures differential expression of the rRNAs from the rest of mtDNA transcripts encoded on the heavy strand $[7,8]$. A second promoter called HSP2 is believed to regulate transcription of a polycistron that corresponds to almost the entire length of mtDNA. While there may be some controversy surrounding this "two-promoter" hypothesis [9], it is clear that the mitochondrial rRNAs are synthesized at a higher rate than the mRNA genes. However,

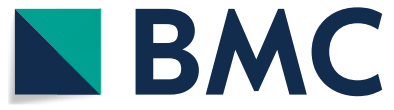

(c) The Author(s) 2020. This article is licensed under a Creative Commons Attribution 4.0 International License, which permits use, sharing, adaptation, distribution and reproduction in any medium or format, as long as you give appropriate credit to the original author(s) and the source, provide a link to the Creative Commons licence, and indicate if changes were made. The images or other third party material in this article are included in the article's Creative Commons licence, unless indicated otherwise in a credit line to the material. If material is not included in the article's Creative Commons licence and your intended use is not permitted by statutory regulation or exceeds the permitted use, you will need to obtain permission directly from the copyright holder. To view a copy of this licence, visit http://creativecommons.org/licenses/by/4.0/. The Creative Commons Public Domain Dedication waiver (http://creativecommons.org/publicdomain/zero/1.0/) applies to the data made available in this article, unless otherwise stated in a credit line to the data. 

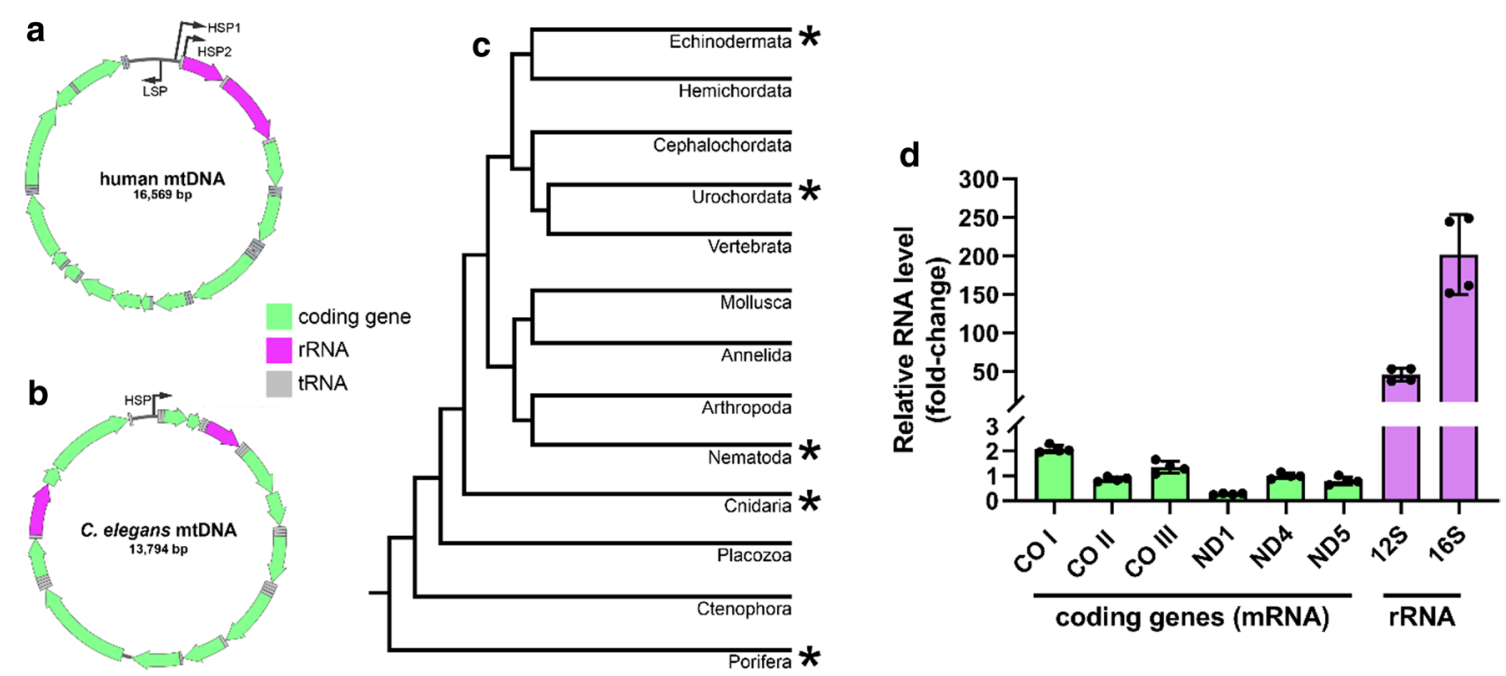

Fig. 1 C. elegans has high levels of mitochondrial rRNA despite their mtDNA organization: a Schematic of human mitochondrial DNA (mtDNA). Human mtDNA encodes 13 essential components of the electron transport chain (depicted in green), 22 tRNAs (gray) and 2 rRNAs (magenta) required for mitochondrial translation. Human mtDNA contains three promoters: heavy strand promoter 1 (HSP1) drives expression of the rRNAs independently from the rest of the genome; heavy strand promoter 2 (HSP2) drives expression of the entire mtDNA heavy strand as a polycistronic transcript; light strand promoter (LSP) drives the transcription of the entire mtDNA light strand. $\mathbf{b}$ Schematic of C. elegans mtDNA. All of the genes in C. elegans mtDNA are presumed to be transcribed from a single heavy strand promoter (HSP) as a single polycistronic transcript. c Metazoan phylogeny. Asterisks indicate taxa containing species with mtDNA organization similar to C. elegans (rRNA encoding genes are distant from each other and mtDNA transcription occurs from a single apparent promoter). Tree branch length is arbitrary. $\mathbf{d}$ Relative RNA levels of $C$. elegans mitochondrial genes normalized to ND4 levels ( $\mathrm{n}=4$ for each of the genes. COI: $\bar{x}=2.07, \mathrm{SD}=0.15 ; \mathrm{COII}: \bar{x}=0.86, \mathrm{SD}=0.09 ; \mathrm{COIII}: \bar{x}=1.35$, $\mathrm{SD}=0.24 ; \mathrm{ND} 1: \bar{x}=0.27, \mathrm{SD}=0.03 ; \mathrm{ND} 4: \bar{x}=1.00, \mathrm{SD}=0.11 ; \mathrm{ND} 5: \bar{x}=0.80, \mathrm{SD}=0.16 ; 12 \mathrm{~S}: \bar{x}=45.61, \mathrm{SD}=8.71 ; 16 \mathrm{~S}: \bar{x}=201.7, \mathrm{SD}=52.24)$

mtDNA organization is not the same across all metazoans. A notable example is that of the model species Caenorhabditis elegans, in which the two rRNA encoding genes in mtDNA are separated by protein coding genes and tRNAs, making it difficult to transcribe them independently from the rest of the genome [10] (Fig. 1b). Organization of mtDNA, similar to C. elegans, in which the rRNAs are distant from each other and not near any rRNA-specific promoters is seen in species across metazoan taxa (phylogeny adapted from [11] (Fig. 1c). Here, we ask whether, and to what extent, $C$. elegans have a high mitochondrial rRNA-to-mRNA ratio.

\section{Main text}

\section{Materials and methods}

\section{Worm strains}

$\mathrm{N} 2$ (C. elegans wild isolate) animals were maintained at $20{ }^{\circ} \mathrm{C}$ on standard nematode growth media (NGM) plates seeded with OP50 E. coli bacteria.

\section{RNA extraction}

For each biological replicate, four $60 \mathrm{~mm}$ NGM plates of mixed-stage N2 worms were washed off of plates with M9 buffer into a single $15 \mathrm{~mL}$ conical tube. Worm suspensions were spun-down at $1300 \mathrm{~g}$ for $5 \mathrm{~min}$, supernatants were aspirated, and worm pellets were transferred to $2 \mathrm{ml}$ RNase-free micro-centrifuge tube. Worm pellets were washed with $1 \mathrm{ml}$ of M9 buffer two additional times to remove residual bacteria. Worm pellets $(\sim 100 \mu \mathrm{l})$ were snap frozen in liquid nitrogen. RNA was extracted using TRIzol ${ }^{\mathrm{TM}}$ (Thermo Scientific \#15596026) as per manufacturer's directions.

\section{CDNA synthesis}

cDNA was synthesized using Maxima $\mathrm{H}$ Minus First Strand cDNA Synthesis Kit (Thermo Scientific \#K1681) following manufacturer's directions. Briefly, $500 \mathrm{ng}$ of RNA from each biological replicate was combined with $1 \mu \mathrm{l}$ of dsDNase, $1 \mu \mathrm{l}$ of $10 \times$ dsDNase buffer and brought-up to 10 ul with nuclease-free $\mathrm{H}_{2} \mathrm{O}$. This mixture was incubated at $37{ }^{\circ} \mathrm{C}$ for 2 min and then immediately returned to ice. Then, to the RNA containing tube, $1 \mu \mathrm{l}$ random hexamer primers, $1 \mu \mathrm{l}$ of $10 \mathrm{mM}$ dNTP, $4 \mu \mathrm{l} 5 \mathrm{x}$ RTase buffer, $1 \mu \mathrm{l}$ of Maxima $\mathrm{H}$ Minus reverse transcriptase, and $3 \mu \mathrm{l}$ of nuclease-free $\mathrm{H}_{2} \mathrm{O}$ were added. The cDNA synthesis reaction was run in a thermocycler: $25^{\circ} \mathrm{C}$ for $10 \mathrm{~min}, 55^{\circ} \mathrm{C}$ for $30 \mathrm{~min}, 85^{\circ} \mathrm{C}$ for $2 \mathrm{~min}, 4^{\circ} \mathrm{C}$ hold. Following cDNA synthesis, cDNA was diluted to $50 \mu \mathrm{l}$ with nuclease-free $\mathrm{H}_{2} \mathrm{O}$ and stored at $-80{ }^{\circ} \mathrm{C}$. 


\section{Droplet digital PCR (ddPCR)}

cDNA dilution: cDNA was diluted in nuclease-free water to run in the dynamic range of ddPCR. Initially, all targets were diluted 1:200. This dilution fell within the dynamic range for the protein-genes. However, at this dilution the rRNA levels saturated the capacity of ddPCR. From this initial result it was determined that a 100x further dilution would be sufficient to accurately quantify rRNA levels. Consequently, cDNA was diluted 1:20,000 for reactions that measured rRNA targets.

ddPCR reaction: In the wells of a Eppendorf ${ }^{\mathrm{TM}}$ 96-Well twin.tec ${ }^{\text {TM }}$ PCR Plate (Fisher Scientific \# E951020303), $2 \mu \mathrm{l}$ of diluted cDNA was combined with $10 \mu \mathrm{l}$ of nuclease-free water, $12.5 \mu \mathrm{l}$ of QX200 ${ }^{\mathrm{TM}} \mathrm{ddPCR}^{\mathrm{TM}}$ EvaGreen Supermix (Bio-Rad \#1864034), and $0.25 \mu \mathrm{l}$ of each corresponding forward and reverse primer $(10 \mu \mathrm{M}$ working stock). Droplets were generated on a QXDx Automated Droplet Generator. Following droplet generation cDNA was amplified: $95{ }^{\circ} \mathrm{C}$ for $5 \mathrm{~min}, 39$ cycles of $95{ }^{\circ} \mathrm{C}$ for $30 \mathrm{~s}$ then $58{ }^{\circ} \mathrm{C}$ for $1 \mathrm{~min}, 4{ }^{\circ} \mathrm{C}$ for $5 \mathrm{~min}, 90^{\circ} \mathrm{C}$ for $5 \mathrm{~min}$, $10{ }^{\circ} \mathrm{C}$ hold. Following cDNA amplification, droplets were read on a QXDx Droplet Reader.

Primers: $12 \mathrm{~S}$ rRNA: CTTGTTCCAGAATAATCGGCT AGACTTG/CTAACCAGGTACTAATCTGCTTTGTTC AAC

16S rRNA: CAGTCTTAGCGTGAGGACATTAAG GTA/CTAACCAATAACTTCATTCATACTGGAACTC

COI: CAGCAGGGTTAAGATCTATCTTAGGTGG/ CGATCAGTTAACAACATAGTAATAGCCCC

COII: CTAGATCAATTAAGTTTAGGTGAACCACG/ CCAAGCATGAATAACATCAGCAGATG

COIII: GCTTGAGGTAAGGATATTGCTATA

GAAGG/GTGTACTGGTACTAGAGCAGCATC

ND1: GCCATCCGTGCTAGAAGACAAAG/CCT

CTAACTAACTCCCTTTCACCTTCAG

ND4: ATTTCCAATTTATTTTTTACATCTTTGATT

ACC/CCCGCTGTGCCTAATTTTAATAG

ND5: GATCTTGGTTACCCAAAGCTATAAGAGC/ GTGTCCTCAAGGCTACCACCTTCTTC

\section{Results and discussion}

To determine the level of mitochondrial rRNAs and mRNAs in C. elegans we extracted RNA from mixedstage populations of wildtype worms followed by first strand cDNA synthesis using random hexamer priming. We then used highly sensitive quantitative droplet digital PCR (ddPCR) to measure mitochondrial mRNA and rRNA steady-state levels. Upon initial quantification, the rRNA transcript counts exceeded the dynamic range of ddPCR while the mRNA levels did not. In fact, cDNA had to be diluted 100-fold further to precisely quantify rRNA levels. Using a generalized linear mixed effects model in $\mathrm{R}$ (package = ImerTest) we compared mitochondrial rRNA levels to mitochondrial mRNA levels after log-transformation of RNA copy number to achieve a normal distribution. We treated RNA type as a fixed effect and replicate and gene as random effects, to give a model of $\log$ (relative copy number) $\sim$ rna type $+(1 \mid$ replicate $)+(1 \mid$ gene $)$. Our analysis revealed that rRNA species levels are 122 times higher than mRNA species levels, after accounting for variance associated with the random effects. A Type II ANOVA on the fixed effect, using Satterthwaite's method to approximate the degrees of freedom from the mixed model, provided an estimated $\mathrm{F}=56.7$ and $\mathrm{p}=0.00028$ (Fig. 1d).

Our finding that C. elegans mitochondrial rRNA levels are over 100 times higher than mitochondrial mRNAs suggests that a high mitochondrial rRNA-to-mRNA ratio is evolutionarily conserved. Furthermore, our finding suggests that multiple strategies have been employed across evolution to ensure a high mitochondrial rRNAto-mRNA ratio. In humans, and many other metazoans, mtDNA organization provides the means for differential expression of the mitochondrial rRNA genes. However, the rRNA genes in C. elegans are separated by coding genes and tRNA genes and there are no apparent promoter sequences directly upstream of rRNA genes. Thus, the mechanisms to achieve high mitochondrial rRNAto-mRNA ratio in humans are likely not available in $C$. elegans, forcing it to rely on potentially different mechanisms. One explanation is that C. elegans mtDNA contains cryptic promoter sequences within coding genes upstream of rRNA genes to facilitate specific expression of rRNAs. This has been proposed as a potential explanation for higher mitochondrial rRNA levels in sea urchins (S. purpuratus) [12]. However, this model is not consistent with the report of a single transcriptional start site in C. elegans mtDNA [13]. Alternatively, the post-transcriptional stability of rRNAs could be higher than that of mRNAs. Indeed, it has been shown that the half-lives of mitochondrial rRNAs in human cell lines are longer than that of mitochondrial mRNAs but not long enough to fully account for the difference in rRNA and mRNA levels [2]. Such increased stability of rRNAs may be a product of their secondary structure or a result of rRNA association with ribosomal proteins or other RNAbinding proteins. Furthermore, we cannot exclude the possibility that other post-transcriptional mechanisms are involved in facilitating high mitochondrial rRNA levels. Future investigations promise to reveal insights into mitochondrial RNA-level regulation. Nevertheless, our finding that $C$. elegans mitochondrial rRNA levels are much higher than mitochondrial mRNAs strongly suggests that a high mitochondrial rRNA-to-mRNA ratio is evolutionarily conserved and is not restrained by mtDNA 
organization. We propose that C. elegans can be used as a complimentary model system to gain insights into the mechanisms employed to maintain a high mitochondrial rRNA-to-mRNA ratio.

\section{Limitations}

The current study reports the observation that rRNA levels are higher than mRNA levels in mitochondria. Determining the mechanism underlying this difference will have to await future studies.

\section{Abbreviations}

mtDNA: Mitochondrial DNA; rRNA: Ribosomal RNA; ddPCR: Droplet digital PCR; HSP: Heavy strand promoter; HSP1: Heavy strand promoter 1; HSP2: Heavy strand promoter 2; LSP: Light strand promoter.

\section{Acknowledgements}

We thank the members of the Patel Laboratory (Bryan L Gitschlag, Cassidy A Johnson, Cait S Kirby, Claudia V Pereira \& Nikita Tsyba) for their valuable feedback on the manuscript. We thank Ann T Tate for help with statistics, and Rama D Gangula in the laboratory of Simon A Mallal for her assistance with ddPCR.

\section{Authors' contributions}

Conceptualization, JPH and MRP; Methodology, JPH and MRP; Investigation, JPH; Resources, MRP; Writing-Original Draft, JPH; Writing-Review \& Editing, JPH and MRP; Visualization, JPH; Supervision, MRP; Funding Acquisition, MRP. All authors read and approved the final manuscript.

\section{Funding}

This work was supported by R01 GM123260 (M.R.P.) and by the support provided to J.P.H. by the Training Program in Environmental Toxicology (5T32ES007028-45).

\section{Availability of data and materials}

All data generated and analyzed during this study are included in this published article.

\section{Ethics approval and consent to participate}

Not applicable.

\section{Consent for publication}

Not applicable.

\section{Competing interests}

The authors declare that they have no competing interests.

\section{Author details}

${ }^{1}$ Interdisciplinary Graduate Program, Vanderbilt University, Nashville, TN 37232, USA. ${ }^{2}$ Department of Biological Sciences, Vanderbilt University, Nashville, TN 37232, USA. ${ }^{3}$ Department of Cell and Developmental Biology, Vanderbilt University, Nashville, TN 37232, USA. ${ }^{4}$ Diabetes Research and Training Center, Vanderbilt University, Nashville, TN 37232, USA.
Received: 29 May 2020 Accepted: 7 July 2020

Published online: 11 July 2020

\section{References}

1. Ojala D, Montoya J, Attardi G. tRNA punctuation model of RNA processing in human mitochondria. Nature. 1981;290:470-4.

2. Gelfand R, Attardi G. Synthesis and turnover of mitochondrial ribonucleic acid in HeLa cells: the mature ribosomal and messenger ribonucleic acid species are metabolically unstable. Mol Cell Biol. 1981;1(6):497-511. http://mcb.asm.org/content/1/6/497.abstract.

3. Mercer TR, Neph S, Dinger ME, Crawford J, Smith MA, Shearwood AMJ, et al. The human mitochondrial transcriptome. Cell. 2011;146(4):645-58. https://doi.org/10.1016/j.cell.2011.06.051.

4. Montoya J, Gaines GL, Attardi G. The pattern of transcription of the human mitochondrial rRNA genes reveals two overlapping transcription units. Cell. 1983;34(1):151-9.

5. Lodeiro MF, Uchida A, Bestwick M, Moustafa IM, Arnold JJ, Shadel GS, et al. Transcription from the second heavy-strand promoter of human mtDNA is repressed by transcription factor a in vitro. Proc Natl Acad Sci. 2012;109(17):6513-8. http://www.pnas.org/content/109/17/6513.abstr act.

6. Zollo O, Tiranti V, Sondheimer N. Transcriptional requirements of the distal heavy-strand promoter of mtDNA. Proc Natl Acad Sci. 2012;109(17):650812. http://www.pnas.org/content/109/17/6508.abstract.

7. Kruse B, Narasimhan N, Attardi G. Termination of transcription in human mitochondria: Identification and purification of a DNA binding protein factor that promotes termination. Cell. 1989;58(2):391-7.

8. Hess JF, Parisi MA, Bennett JL, Clayton DA. Impairment of mitochondrial transcription termination by a point mutation associated with the MELAS subgroup of mitochondrial encephalomyopathies. Nature. 1991;351(6323):236-9. https://doi.org/10.1038/351236a0.

9. D'Souza AR, Minczuk M. Mitochondrial transcription and translation: overview. Garone C, Minczuk M, editors. Essays Biochem. 2018;62(3):309-20. https://doi.org/10.1042/EBC20170102.

10. Okimoto R, Macfarlane JL, Clary DO, Wolstenholme DR. The mitochondrial genomes of two nematodes, Caenorhabditis elegans and Ascaris suum. Genetics. 1992;130(3):471-98.

11. Elphick MR, Mirabeau O, Larhammar D. Evolution of neuropeptide signalling systems. J Exp Biol. 2018;221(3):jeb151092. http://jeb.biologists.org/ content/221/3/jeb151092.abstract.

12. Elliott DJ, Jacobs HT. Mutually exclusive synthetic pathways for sea urchin mitochondrial rRNA and mRNA. Mol Cell Biol. 1989; 9(3):1069-82. http:// mcb.asm.org/content/9/3/1069.abstract.

13. Blumberg A, Rice EJ, Kundaje A, Danko CG, Mishmar D. Initiation of mtDNA transcription is followed by pausing, and diverges across human cell types and during evolution. Genome Res. 2017;27(3):362-73.

\section{Publisher's Note}

Springer Nature remains neutral with regard to jurisdictional claims in published maps and institutional affiliations.

Ready to submit your research? Choose BMC and benefit from

- fast, convenient online submission

- thorough peer review by experienced researchers in your field

- rapid publication on acceptance

- support for research data, including large and complex data types

- gold Open Access which fosters wider collaboration and increased citations

- maximum visibility for your research: over 100M website views per year

At BMC, research is always in progress.

Learn more biomedcentral.com/submissions 